\title{
Drug-seeking behaviours for codeine-acetaminophen and tramadol-acetaminophen prescriptions: a pilot study
}

\author{
Nevio Cimolai* \\ Faculty of Medicine, The University of British Columbia, Vancouver, British Columbia, Canada
}

\begin{abstract}
A pilot study was conducted among primary care patients who presented with complaints of pain. This hypothesis-generating audit was conducted to assess the frequency of drug-seeking behaviour among 56 primary care patients for either codeine-acetaminophen $(\mathrm{C}-\mathrm{A})(\mathrm{n}=39)$ or tramadol-acetaminophen $(\mathrm{T}-\mathrm{A})(\mathrm{n}=17)$ when such prescriptions were given. Drug-seeking behaviour was significantly more common among those who received $\mathrm{C}-\mathrm{A}$ ( $\mathrm{p}=0.01$ ). There were no differences between C-A and T-A groups for gender, age, prior codeine use, dominant clinical indication, disability status/claim, employment status, vehicular injury, work injury, presence of chronic pain syndrome, specialty consultant attendance, or psychiatric co-morbidity ( $p>0.05$ for all comparisons). In the $\mathrm{C}$ - $\mathrm{A}$ prescription group, there was a trend, albeit insignificant ( $\mathrm{p}=0.19$ ), for more drug-seeking behaviour among younger patients (average age 56.5 yrs. versus 51.9 yrs. for non-drug-seeking and drug-seeking individuals). When the analysis was stratified for older age, however, drug-seeking behaviour did not associate with age. Drug-seeking behaviour is greater for $\mathrm{C}-\mathrm{A}$ than $\mathrm{T}-\mathrm{A}$ in this preliminary assessment, and larger studies with a multivariate analysis are warranted to confirm this finding.
\end{abstract}

\section{Introduction}

Medical treatment for pain is a common issue among all adult age groups in primary care. As bonafide indications for treatment should be accommodated by effective pharmacotherapy when needed, the use of narcotics is plagued by misuse and malingering. The latter often creates a 'Catch 22' for physicians in many circumstances [1]. Physicians are sensitive to the need for proper pain management, but prescriptions may become more liberal over time. On the contrary, patients who abuse pain medications not uncommonly learn the strategy of extracting prescriptions from prescribers. Opioid analgesic use also has its limitations for the elderly [2].

Codeine-acetaminophen (C-A) combinations are among the most prescribed pain medications in primary practice worldwide. Drug-seeking behaviour for this combination is well known, and black market/street availability is commonplace in Canada. The more contemporary availability of a comparable pain medication in tramadol-acetaminophen (T-A) poses the potential added benefit of mitigating drug-seeking behaviour and drug abuse in the community if tramadol does not prompt euphoria to the same extent as codeine. In addition, the novelty of a pain medication may not prompt recognition by the drug-abusing recipient. A prospective audit was therefore conducted for C-A and T-A drug-seeking behaviours to gauge any possible differences. The purpose of this study was also to determine if there was sufficient reason to believe that a larger prospective review would be of future value.

\section{Methods}

A single observer audit was conducted for fifty-six patients attending three different primary care clinics in the Lower Mainland of British Columbia over the period November, 2013 to May, 2014. Both primary and secondary prescriptions were included. Data were tabulated for each consecutive patient using a standard template. Only adults over eighteen years of age were considered. Various demographic and clinical variables were considered as detailed in Tables 1 and 2.

Drug-seeking behaviour was predefined in anticipation of the audit. For the purposes of this study, a hybrid subjective/objective definition was utilized. Drug-seeking behaviour was considered as a set of behaviours, two or more, in which a patient was believed to have established a directed and/or concerted effort to obtain either C-A or T-A. Such behaviours could include among the following: 1) significant discrepancy in requesting an early refill or prematurely expiring an existing prescription, 2) a repeat admission of lost or stolen prescriptions, 3) threatening behaviours, 4) complaints of pain repetitively without an organic basis, 5) perseveration of requests when prescriptions were denied, 6) obvious inconsistencies about pain or medical history, and 7) other manipulative behaviour in regards to medication acquisition and use.

As this was an exploratory study to determine if a large prospective study would be of further interest, univariate analyses were conducted with the use of standard statistical methods. A correction for multiple analyses was not made given the exploratory nature of assessment. Multivariate analyses were not conducted given the relatively small scale of patient numbers.

\section{Results}

A total of fifty-six patients were assessed ( 33 male, 23 female). Thirty-nine were prescribed or sought A-C; seventeen were prescribed

Correspondence to: Nevio Cimolai MD, $\operatorname{FRCP}(C)$, Department of Pathology and Laboratory Medicine, Children's and Women's Health Centre of British Columbia Vancouver, British Columbia, Canada, V6H3V4, E-mail: ncimolai@mail.ubc.ca

Key words: codeine, tramadol, prescription, treatment, drug abuse

Received: February 04, 2015; Accepted: March 19, 2015; Published: March 23, 2015 
Table 1. Univariate analyses for demographic and clinical variables among patients using codeine-acetaminophen (C-A) or tramadol-acetaminophen (T-A).

\begin{tabular}{|l|c|c|c|}
\hline & C-A & T-A & \\
\hline Prior C-A use & (n=39) & (n=17) & P \\
\hline Prior T-A use & 35 & 13 & 0.19 \\
\hline Drug-seeking that category & 4 & 5 & 0.07 \\
\hline Night-time use only & 7 & 0 & 0.01 \\
\hline Neck/back use indications & 22 & 7 & 0.07 \\
\hline Chronic pain syndrome & 32 & 6 & 0.15 \\
\hline Consultant attending & 20 & 12 & 0.34 \\
\hline Psychiatric co-morbidity & 13 & 5 & 0.25 \\
\hline Employed & 14 & 8 & 0.77 \\
\hline Disability claim & 20 & 6 & 0.43 \\
\hline Motor vehicle accident & 10 & 2 & 0.27 \\
\hline Work-related pain & 5 & 6 & 0.25 \\
\hline Concomitant other opioid & 1 & 3 & 0.05 \\
\hline Prior other opioid & 10 & 8 & 0.12 \\
\hline Secondary treatment & & 7 & 0.02 \\
\hline prescription & 29 & & 0.12 \\
\hline Side effects & & 0 & \\
\hline
\end{tabular}

Table 2. Univariate analyses for demographic and clinical variables among patients using codeine-acetaminophen (C-A) with or without drug-seeking behaviour.

\begin{tabular}{|l|c|c|c|}
\hline & Drug-seek & Non-seeking & \\
\hline Night-time use only & $(\mathbf{n}=\mathbf{1 2})$ & $\mathbf{( n = 2 7 )}$ & $\mathbf{P}$ \\
\hline Neck/back use indications & 1 & 6 & 0.30 \\
\hline Chronic pain syndrome & 6 & 16 & 0.42 \\
\hline Consultant attending & 11 & 21 & 0.30 \\
\hline Psychiatric co-morbidity & 7 & 13 & 0.56 \\
\hline Employed & 6 & 7 & 0.14 \\
\hline Disability claim & 4 & 10 & 0.82 \\
\hline Motor vehicle accident & 8 & 12 & 0.20 \\
\hline Work-related pain & 3 & 7 & 0.80 \\
\hline Concomitant other opioid & 1 & 4 & 0.58 \\
\hline Prior other opioid & 7 & 0 & 0.55 \\
\hline Secondary treatment prescription & 11 & 3 & 0.04 \\
\hline Long-term use ( $\mathbf{3}$ months) & 11 & 17 & 0.10 \\
\hline
\end{tabular}

or sought T-A. Among the C-A group, twenty-five prescriptions were for $\mathrm{C}$-A-caffeine and fourteen were for $\mathrm{C}$-A fixed combinations. There was no significant difference in gender between $\mathrm{C}-\mathrm{A}$ and $\mathrm{T}-\mathrm{A}$ groups $(p=0.56)$. In the $C-A$ group, there were twelve patients deemed drugseeking: eleven for C-A and one for both C-A and T-A. In the T-A group, three manifested drug-seeking behaviours, but these were directed to $\mathrm{C}-\mathrm{A}$, not $\mathrm{T}-\mathrm{A}$. Table 1 demonstrates comparisons among the $\mathrm{C}-\mathrm{A}$ and $\mathrm{T}-\mathrm{A}$ groups for demographic and clinical variables. There was a significant association of drug-seeking behaviour for C-A $(\mathrm{p}=0.01)$. Consistent with the latter, patients prescribed C-A were more likely to be given repeat prescriptions $(\mathrm{p}=0.02)$. The nature of injury, the attendance of consultants, and psychiatric co-morbidity was not associated with either category of drug use. Table 2 bears data for the comparison of drug-seeking and non-seeking subsections of the C-A group. Of note, C-A drug-seeking patients were more likely to have used another opioid medication in the past. Table 3 explores age stratification for drug-seeking and non-seeking categories of the C-A group given the trend for average age which seemed to be directed
Table 3. Age stratification and drug-seeking behaviour for patients seeking or prescribed codeine-acetaminophen.

\begin{tabular}{|c|c|c|c|}
\hline Age & Drug-seek & Non-seeking & P \\
\hline Average & 51.9 yrs. & 56.6 yrs. & 0.14 \\
\hline$<60 \mathrm{yrs}$ & 9 & 17 & 0.71 \\
\hline$\geq 60 \mathrm{yrs}$ & 3 & 10 & \\
\hline$<65 \mathrm{yrs}$ & 11 & 21 & 0.55 \\
\hline$\geq 65 \mathrm{yrs}$ & 1 & 6 & \\
\hline
\end{tabular}

towards more drug-seeking behaviour for younger age. No association was evident for older ages.

\section{Discussion}

Tramadol, alone or in combination, has proven to be effective in pain management [3-5]. It has been used for decades elsewhere in the world and is increasingly gaining popularity in Canada and in several compositions. Few good studies of direct C-A and T-A comparisons are published [6].

Most reports of tramadol use have suggested low addiction potential in comparator studies [7-12]. Similar belief was maintained in North America when the drug and its combinations were introduced. Indeed, tramadol-containing formulations are often not on controlled substance prescription lists. Formulary concerns mainly relate to cost. In the last few years, there have been increasing reports of tramadol misuse [13,14], albeit more commonly with high doses [15]. Inevitably, some misuse will likely occur when mood-altering effects are experienced. Some patients may seek tramadol for overuse or for compulsive behaviours. Whereas such behaviour is likely to be experienced to some degree, our pilot study indicates that the frequency of such is much lower for T-A than C-A.

The cost of T-A may prove to be the major limiting factor both for patients and providers. One recent comparison in pharmacy direct cost (without prescription fees; British Columbia, Canada) provided the following estimates: T-A _ $\$ 82.50 / 100$ units, C-A _ $\$ 14.04 / 100$ units, and C-A-caffeine _ \$8.62-9.93/100 units. These dramatic differences in cost are only likely to be minimally altered by bulk purchasing for the provider. Since new medications like tramadol may not be covered by public formularies, prescribers may shy from prescribing tramadol formulations. Chronic pain patients tend to stratify into lower income groups. A cost-benefit analysis would be of interest but somewhat difficult to accomplish given that one variable is likely to be the cost of fueling addiction or drug-seeking behaviour.

The key finding of our exploratory study, despite the small number of patients enrolled, is that T-A is less often sought after by those patients manifesting drug-seeking behaviours. Patients prescribed C-A are more likely to be seeking repeat prescriptions and for prolonged periods. Stratification for age did not show differences for patients in the senior categories. Therefore, even if T-A is abused by some, it may yet prove highly beneficial if the rate of abuse is much less than that for C-A. Larger studies which include multivariate analyses could be conducted to further assess these preliminary findings. Our pilot study provides the grounds for hypothesis testing studies which will be of great value if these findings are further confirmed.

\section{References}

1. Savage SR (1999) Opioid use in the management of chronic pain. Med Clin North Am 83: 761-786. [Crossref]

2. Forman WB (1996) Opioid analgesic drugs in the elderly. Clin Geriatr Med 12: 489500. [Crossref] 
3. Müller FO, Odendaal CL, Müller FR, Raubenheimer J, Middle MV, et al. (1998) Comparison of the efficacy and tolerability of a paracetamol/codeine fixeddose combination with tramadol in patients with refractory chronic back pain. Arzneimittelforschung 48: 675-679. [Crossref]

4. Fricke JR Jr, Karim R, Jordan D, Rosenthal N (2002) A double-blind, single-dose comparison of the analgesic efficacy of tramadol/acetaminophen combination tablets, hydrocodone/acetaminophen combination tablets, and placebo after oral surgery. Clin Ther 24: 953-968. [Crossref]

5. Chaparro LE, Furlan AD, Deshpande A, Mailis-Gagnon A, Atlas S, et al. (2013) Opioids compared to placebo or other treatments for chronic low-back pain. Cochrane Database Syst Rev 8: CD004959. [Crossref]

6. Mullican WS, Lacy JR, TRAMAP-ANAG-006 Study Group (2001) Tramadol/ acetaminophen combination tablets and codeine/acetaminophen combination capsules for the management of chronic pain: a comparative trial. Clin Ther 23: 1429-1445. [Crossref]

7. Flohé L, Arend I, Cogal A, Richter W, Simon W (1978) Clinical study on the development of dependency after long-term treatment with tramadol (author's transl). Arzneimittelforschung 28: 213-217. [Crossref]

8. Richter W, Barth H, Flohé L, Giertz H (1985) Clinical investigation on the development of dependence during oral therapy with tramadol. Arzneimittelforschung 35: 1742 1744. [Crossref]
9. Cicero TJ, Adams EH, Geller A, Inciardi JA, Muñoz A, et al. (1999) A postmarketing surveillance program to monitor Ultram (tramadol hydrochloride) abuse in the United States. Drug Alcohol Depend 57: 7-22. [Crossref]

10. Radbruch L, Grond S, Lehmann KA (1996) A risk-benefit assessment of tramadol in the management of pain. Drug Saf 15: 8-29. [Crossref]

11. Cicero TJ, Inciardi JA, Adams EH, Geller A, Senay EC, et al. (2005) Rates of abuse of tramadol remain unchanged with the introduction of new branded and generic products: results of an abuse monitoring system, 1994-2004. Pharmacoepidemiol Drug Saf 14: 851-859. [Crossref]

12. Adams EH, Breiner S, Cicero TJ, Geller A, Inciardi JA, et al. (2006) A comparison of the abuse liability of tramadol, NSAIDs, and hydrocodone in patients with chronic pain. J Pain Symptom Manage 31: 465-476. [Crossref]

13. Dart RC, Dasgupta N, Bailey JE, Spiller HA (2011) Interpreting poison center call volume associated with tramadol. Ann Pharmacother 45: 424. [Crossref]

14. Spiller HA, Scaglione JM, Aleguas A, Foster H, Durback-Morris L, et al. (2010) Effect of scheduling tramadol as a controlled substance on poison center exposures to tramadol. Ann Pharmacother 44: 1016-1021. [Crossref]

15. Babalonis S, Lofwall MR, Nuzzo PA, Siegel AJ, Walsh SL (2013) Abuse liability and reinforcing efficacy of oral tramadol in humans. Drug Alcohol Depend 129: 116-124. [Crossref]

Copyright: (C2015 Cimolai N. This is an open-access article distributed under the terms of the Creative Commons Attribution License, which permits unrestricted use, distribution, and reproduction in any medium, provided the original author and source are credited. 